\title{
REVITALISASI LEGENDA DANAU LAU KAWAR MELALUI KOMIK
}

\author{
Delvi K. Parapat ${ }^{1}$, Pani Flora Marbun ${ }^{2}$, Salsabila Handayani Nst ${ }^{3}$, Yeni Elsabet Siregar ${ }^{4}$, \\ Dian Syahfitri ${ }^{5}$ \\ Universitas Prima Indonesia ${ }^{1}$, Universitas Prima Indonesia ${ }^{2}$, Universitas Prima Indonesia ${ }^{3}$, \\ Universitas Prima Indonesia ${ }^{4}$, Universitas Prima Indonesia ${ }^{5}$ \\ Pos-el: delvkris26@gmail.com¹, marbunpaniflora@gmail.com², sabiylnst@gmail.com³, \\ yenielsabeth19@gmail.com ${ }^{4}$, diansyahfitri@unpri.mdn.ac.id ${ }^{5}$
}

\begin{abstract}
ABSTRAK
Legenda Danau Kawar adalah cerita rakyat dari Kabupaten Karo yang menceritakan seorang nenek yang mengutuk Desa Kawar menjadi Danau Lau Kawar. Bentuk cerita tentang asal mula Danau Lau Kawar juga belum banyak diketahui oleh masyarakat, hal ini dikarenakan sumber-sumber hiburan alternatif yang menarik minat Masyarakat khususnya anak-anak. maka dari itu, anak-anak telah kehilangan minat untuk mengetahui berbagai macam faktor khususnya Legenda. Metode penelitian yang digunakan antara lain adalah pendekatan kualitatif untuk menggali informasi terhadap Cerita danau lau kawar. Sebagai subjek perancangan utama, seperti wawancara kepada informan atau masyarakat sekitar. Hasil penelitian ini diformulasikan dalam konsep penceritaan ulang Legenda danau lau kawar. Penggunaan media komik sebagai media dapat menjadi salah satu usaha pelestarian cerita rakyat. Media komik memberikan gaya penceritaan dengan narasi dan ilustrasi serta memudahkan akses terhadap cerita yang sebelumnya jarang diketahui. penerapan media komik ini dalam bentuk produk makanan.
\end{abstract}

Kata Kunci: Revitalisasi, Legenda, Komik.

\section{ABSTRACT}

The legend of Lake Kawar is the folklore of the District Karo that tells a grandmother who cursed the Village Kawar be Lake Lau Kawar. The form of stories about the origin of Lake Lau Kawar also has not been known by the public, this is because the entertainment sources alternative attracted the interest of the ASEAN, especially children. Then of it's, children have lost interest to find out a variety of a factor in particular of Legend. The research used among other is kualitatif approach to dig the information against Story of the lake lau kawar. As the subject of major, such as the interview to the informant or around. The results formulated in the concept of storytelling anniversary of Legend of the lake lau kawar. The use of the media comic as a medium can be one of the business preservation of folklore. The media comic give style storytelling with the narrative and illustration as well as facilitate access to the story before little-known. Implementation of the media this comic in the form of the product food.

Keywords: Revitalization, Legend, Comics.

\section{PENDAHULUAN}

Indonesia merupakan negara yang kaya akan Legenda salah satu diantaranya adalah legenda Batak Karo yang terdapat di Sumatera Utara, legenda dari masyarakat Batak Karo yang umumnya bermukim di Kabupaten Karo. Legenda Batak Karo ini sangat banyak jumlahnya, baik yang diungkapkan dalam bentuk lisan maupun yang telah diungkapkan dalam bentuk tulisan. Secara umum Legenda ini masih 
diungkapkan dalam bahasa Batak Karo. Hal ini mengingat bahwa secara geografis bahasa Batak Karo masih dipergunakan sebagai sarana komunikasi oleh suku Batak Karo yang tinggal di daerah asal maupun perantauan.

Menurut Danandjaja, (2002:66) Legenda adalah cerita prosa rakyat yang dianggap oleh empunya cerita sebagai suatu kejadian yang sungguh-sungguh pernah terjadi. Masyarakat yakin bahwa legenda-legenda pernah terjadi pada masa masa yang lama. Legenda memiliki kandungan nilai-nilai luhur yang bermanfaat bagi kehidupan masyarakat. Mengingat begitu besar makna legenda bagi masyarakat pendukungnya, maka perlu d iadakan suatu kajian mengenai legenda legenda yang masih dikenal dan hidup pada masyarakat tertentu.

Danau lau kawar adalah danau yang berada di desa Kutagugung kecamatan Naman Teran. Danau lau kawar ada di kaki gunung sinabung. Danau ini menampilkan keindahan dan juga memiliki cerita tersembunyi dibalik terjadinya danau Lau Kawar. Namun, dikarenakan erupsi gunung sinabung, pengujung danau lau kawar semakin menurun sehingga cerita dan keindahan danau lau kawar sudah kurang diketahui oleh masyarakat.

Legenda dapat digolongkan seperti yang dikemukakan oleh brunvand dalam danandjaja (2002:67) yaitu legenda keagamaan, legenda perseorangan, legenda alam dan legenda setempat. Namun peneliti memilih salah satu yaitu: legenda setempat, dimana mengandung cerita yang berhubungan dengan terjadinya suatu tempat.

Salah satunya dalam cerita legenda danau lau kawar yang menceritakan seorang nenek yang mengutuk desa kawar menjadi danau lau kawar yang saat ini masih ada. Saat ini, menceritakan legenda sudah tidak lagi dibudayakan. Anak-anak menjadi tidak berminat dengan lagenda. Hal ini dikarenakan kemajuan teknologi yang semakin canggih dengan menawarkan sumber hiburan alternatif yang menarik minat masyarakat khususnya anakanak. Kecanggihan teknologi telah melunturkan budaya lokal. Maka dari itu, kalangan anak-anak saat ini telah kehilangan minat untuk mengetahui berbagai macam legenda.

Hal tersebut berdampak pada kec intaan masyarakat khususnya anak-anak terhadap foklor yang ada diberbagai daer ah. Perlu diketahui ternyata bentuk cerita tentang asal mula Danau Lau Kawar juga belum banyak diketahui oleh masyarakat. Sehingga peneliti menganggap hal tersebut sangat penting dalam menambah wawasan masyarakat. Masyarakat terdahulu menceritakan legenda kepada anak sebagai tradisi.

Melihat kenyataan ini, peneliti berinisiatf untuk melakukan penelitian terhadap Revitalisasi Lagenda Danau Lau Kawar Melalui Komik. Melalui Komik masyarakat terutama anak-anak menjadi lebih tertarik untuk mengetahui legenda danau lau kawar terkhusus pada masyarakat yang bermukim di daerah danau lau kawar. Berdasarkan hasil wawancara peneliti, terdapat beberapa masyarakat yang tidak sepenuhnya mengetahui cerita legenda danau lau kawar. Oleh karena itu, peneliti mengangkat judul tersebut.

Berdasarkan Latar Belakang Masalah yang diuraikan tersebut, maka yang menjadi identifikasi penelitian ini adalah kemajuan teknologi yang semakin canggih dengan menawarkan sumber hiburan alternatif yang menarik minat masyarakat khususnya anak-anak. Selain itu, minimnya kebiasaan mayarakat dalam memperkenalkan lagenda kepada anaknya. Oleh karena itu peneliti bertujuan untuk merevitalisasikan legenda danau lau kawar dalam bentuk Komik untuk meningkatkan legenda supaya lebih diminati oleh masyarakat dan anak-anak. 
Berdasarkan identifikasi masalah di atas maka peneliti merumuskan masalah antara lain: (a) Bagaimana legenda danau lau kawar? (b) Bagaimana revitalisasi legenda danau lau kawar dalam bentuk Komik ?.

Berdasarkan rumusan masalah di atas maka peneliti merumuskan tujuan penelitian antara lain: (a) untuk mengetahui legenda danau lau kawar (b) untuk mengetahui hasil revitalisasi legenda danau lau kawar dalam Komik.

Adapun manfaat dari penelitian yang akan dilakukan ialah untuk menumbuhkan keinginan masyarakat khususnya anak-anak dalam melestarikan cerita rakyat dan meningkatkan cerita danau lau kawar dengan menggunakan media animasi yang dirancang dengan tokoh-tokoh karakter yang dapat dibuat sedemikian rupa sehingga mempunyai sifat dan tingkah laku seperti manusia.

\section{METODE PENELITIAN}

Lokasi penelitian berada di Desa Kutagugung, Kecamatan Naman teran, di bawah kaki Gunung Sinabung, Kabupaten Karo, Provinsi Sumatera Utara. Waktu penelitian dilakukan pada tanggal 23 Februari 2019.

Metode yang digunakan dalam revitalisasi legenda lau kawar ini adalah metode kualitatif. Menurut Sugiyono (2009:15), metode penelitian kualitatif adalah penelitian yang digunakan untuk menyelidiki, menemukan, menggambarkan, dan menjelaskan kualitas atau keistimewaan dari pengaruh sosial yang tidak dapat dijelaskan, diukur atau digambarkan melalui pendekatan kualitatif. Maka dari itu, peneliti harus memiliki bekal teori dan wawasan yang luas agar dapat melakukan wawancara secara langsung terhadap Informan.

Data dalam penelitian ini adalah teks lisan dan tertulis dari naskah, cerita, informasi, maupun transkrip teks dari informan mengenai cerita Legenda
Danau Lau Kawar Sumber data dalam penelitian ini, yaitu (1) informan; dan (2) dokumentasi tertulis. Informan dalam penelitian ini yaitu tokoh masyarakat, warga yang bermukim di Kabupaten Karo, mempunyai pengetahuan lengkap tentang keberadaan dan cerita tentang Legenda Danau Lau Kawar. Dokumentasi tertulis yang dimaksud yaitu berupa situs internet yang berhubungan dengan keberadaan serta cerita Legenda Danau Lau Kawar.

Teknik pengumpulan data dalam penelitian ini meliputi wawancara, dan studi kepustakaan. Instrumen pengumpulan data yang digunakan untuk mengumpulkan data dalam penelitian ini berupa wawancara, dan panduan pemilihan dokumentasi. Data yang terkumpul akan terjamin kevaliditasnya jika peneliti sendiri yang terjun ke lapangan. Oleh karena itu, penelitian ini melibatkan peneliti secara langsung di lapangan.

Menurut Miles dan Humbermen (1984), Teknik analisis data dalam penelitian ini yaitu: (a) Tahap Redukasi Data, dimana peneliti mencatat sekaligus mengklasifikasikan hasil wawancara informan dengan lokasi yang berbeda dan membuat ringkasan sementara sesuai dengan informan yang diwawancarai. (b) Tahap Penyajian Data, pada tahap ini, peneliti menyusun data yang relevan sehingga menghasilkan informasi yang dapat disimpulkan dan memiliki makna. (3) Tahap Penarikan Kesimpulan dan Verifikasi, pada tahap ini, peneliti masih memperoleh kesimpulan sementara dan mengalami perubahan apabila ditemukan bukti-bukti lain.

Prosedur penelitian adalah bagian yang penting di dalam suatu penelitian. Adapun langkah-langkah prosedur penelitian yaitu: (A) Tahap Perencanaan, Pada tahap ini peneliti masih sampai pada kegiatan menyusun perumusan masalah, penyusunan rancangan penelitian dan menentukan 
bagaimana cara dalam pengumpulan data. Sesuai dengan uraian sebelumnya, pada penelitian ini terdapat rumusan masalah yaitu: (a) Bagaimana legenda danau lau kawar? (b) Bagaimana revitalisasi legenda danau lau kawar dalam bentuk vidio animasi? (B) Tahap Pelaksanaan, Pada tahap ini meliputi pengumpulan data, analisis data dan penarikan kesimpulan. Pada tahap pengumpulan data, peneliti menggunakan dua tahap yakni mengumpulkan data dari informan guna untuk memperoleh bagaimana legenda danau lau kawar dan tahap analisis data dari hasil wawancara. Pada tahap terakhir yaitu penarikan kesimpulan berupa jawaban dari rumusan masalah.

(C) Tahap Pengumpulan Laporan, Pada tahap ini setelah semua data yang dibutuhkan sudah terkumpul, dianalisis dan sudah disimpulkan. Tahap ini yaitu tahap memindahkan hasil penelitian yang telah diperoleh kedalam bentuk laporan yang sifatnya ilmiah.

\section{HASIL DAN PEMBAHASAN Hasil Penelitian}

Hasil penelitian ini memuat tentang cerita yang meliputi asal-usul cerita Legenda Danau Lau Kawar dengan hasil paparan data melalui transkrip yang kemudian di ubah dalam bentuk komik. (a) untuk mengetahui cerita Legenda Danau Lau Kawar (b) untuk mengetahui cerita Legenda Danau Lau Kawar Melalui Komik. Media yang akan dipakai adalah komik, dimana komik tersebut akan bercerita tentang legenda Danau Lau Kawar tersebut. Alasan kenapa peneliti memilih komik adalah karena generasi milenial cenderung tertarik dengan sesuatu yang berbeda. Komik tersebut rencananya akan dicantumkan dibungkus makanan anak-anak supaya ketika anak tersebut membeli atau memakan makanan yang berbungkus komik tersebut secara otomatis mungkin akan tertarik untuk membaca komik Legenda Danau Lau
Kawar tersebut dan akan mengetahui ceritanya. Namun peneliti tidak secara langsung mencantumkan semua cerita Legenda Danau Lau Kawar tersebut melainkan secara episode yaitu sekitar empat atau lima episode. Semakin banyak makanan berbungkus komik Legenda Danau Lau Kawar yang dibeli oleh masyarakat maka secara otomatis semakin banyak pula yang akan mengetahui cerita dari Legenda Danau Lau Kawar.

Berikut cerita legenda danau lau kawar yang akan diceritakan dalam bentuk Komik:

Pada Zaman dahulu di sebuah desa yang terletak di Kabupaten Karo terdapat desa yang bernama Desa Kawar. Desa ini merupakan desa subur dan dikelilingi oleh pemandangan yang indah. Penduduk yang tinggal di sana menjadikan bertani sebagai mata pencahariannya. Suatu hari, desa tersebut menghasilkan 2 kali lipat hasil panen dari tahun sebelumnya. Lumbunglumbung penduduk terlihat penuh dan bahkan ada yang sudah tidak muat lagi. Penduduk sangat senang dan juga tidak lupa untuk bersyukur kepada Tuhan sebab telah memberikan hasil panen yang melimpah ruah. Sebagai bentuk rasa syukur, Penduduk desa mengadakan acara adat setiap tahunnya.

Semua penduduk desa memeriahkan acara itu. Ibu-ibu yang tinggal di desa bergotong-royong memasak makanan yang akan disantap. Desa lau kawar tampak ramai dan semarak tak hanya itu, bahkan juga terdengar suara gondang yang mengiringi acara pesta adat tersebut. Tetapi di salah satu keluarga ada seorang nenek yang tidak dapat ikut ke acara tersebut. Nenek tidak sanggup menghadiri acara dikarenakan kondisi tubuh nya yang sedang sakit. Meski begitu, tidak ketinggalan pula anak, menantu maupun cucunya turut hadir dalam acara itu. 
Keesokan harinya setelah mereka pergi, tinggallah nenek seorang diri terbaring tak berdaya di kasur. Padahal, nenek ingin sekali ikut merayakan pesta adat tersebut. Nenek meratapi nasipnya dan membayangkan keadaan di acara tersebut. Dengan suara gondang yang membuat nenek mengenang kembali masa-masa ketika nenek remaja dahulu. Namun semua telah menjadi kenangan dalam hidup nenek. Sekarang, nenek hanya bisa menikmati masa tuanya dengan berbaring di kasur. Tidak seorangpun yang mengajak nenek berbicara bahkan anak, menantu dan cucunya juga begitu.

Hari-harinya hanya bisa menangis, nenek merasa seakan-akan dirinya seperti sampah sebab tak ada yang perduli padanya. Disiang hari, makanan yang dimasak sudah siap untuk disajikan. Ada daging panggang lembu, babi, ayam dan masih banyak jenis makanan lainnya. Penduduk berkumpul dan menyantap makanan yang telah di sajikan dan sesekali tertawa karena diantara mereka ada yang membuat lelucon. Semua penduduk gembira saat itu sampai-sampai membuat anak , menantu, dan cucu lupa bahwa ibunya yang sedang sakit dirumah sama sekali belum makan dari pagi. Nenek merasa sangat lapar.

Besar harapan nenek agar anak dan menantunya segera menghantarkan makanan ke rumah. Nenek menunggu kedatangan makanan tersebut tetapi tak satupun ada yang mengahantarkan makanan ke rumah. nenek kembali menangis meratapi dirinya yang malang. Acara pesta adat berlangsung dengan hikmat. Setelah penduduk selesai makan bersama, anak tersebut baru ingat bahwa ibunya belum makan. Akhirnya anak menyuruh istrinya untuk menyiapkan makanan. Kemudian menantu dari nenek memerintahkan cucu nenek tersebut untuk mengantar makanan kerumah.

Akhirnya cucu langsung berlari pulang ke rumah dengan membawa bungkusan. sesampainya di rumah, anak memberikan bungkusan yang di bawanya kenenek dan kemudian langsung lari ke acara pesta adat. Nenek sangat gembira. Dalam keadaan yang sedang lapar tiba-tiba ada yang menghantarkan makanan untuknya. Nenek segera membuka bungkusan tersebut berhubung nenek sudah sangat lapar. Ketika nenek membuka bungkusan itu, nenek sangat kecewa dan sedih . ternyata bungkusan itu berisi sisasisa makanan penduduk.

Dalam bungkusan itu terdapat potongan tulang-tulang yang hampir habis dagingnya. Nenek tidak mengetahui sebenarnya apa yang telah terjadi. Nenek mengira bahwa cucunya memakan bungkusan di tengah perjalanan. Nenek merasa sangat terhina dan merasa bahwa dirinya sama seperti binatang. Air matanyapun tak terbendung lagi. Kemudian nenek berdoa kepada Tuhan agar mengutuk anak, menantu dan cucunya. "Ya, Tuhan! Mereka telah berbuat durhaka kepadaku. Berilah mereka pelajaran!" Setelah kalimat itu selesai diucapkan , tiba-tiba di sekitar desa lau kawar terjadi gempa bumi yang sangat dasyat.

Langit yang cerahpun seketika berubah menjadi mendung dan dilengkapi dengan petir yang menggelegar seakan memecah langit dan tak lama kemudian hujan turun selebatlebatnya. Seluruh penduduk yang awalnya bersuka-ria tiba-tiba panik dan ketakutan. Penduduk menangis dan menjerit meminta tolong. Tidak ada satupun yang bisa menghindar dari keganasan alam yang sungguh mengerikan itu. Akhirnya desa kawar yang subur dan makmur tiba-tiba tenggelam dan beberapa hari kemudian, desa itu berubah menjadi kawah besar yang digenangi air.

Berikut hasil Revitalisasi Legenda Danau Lau Kawar Dalam Bentuk Komik: 

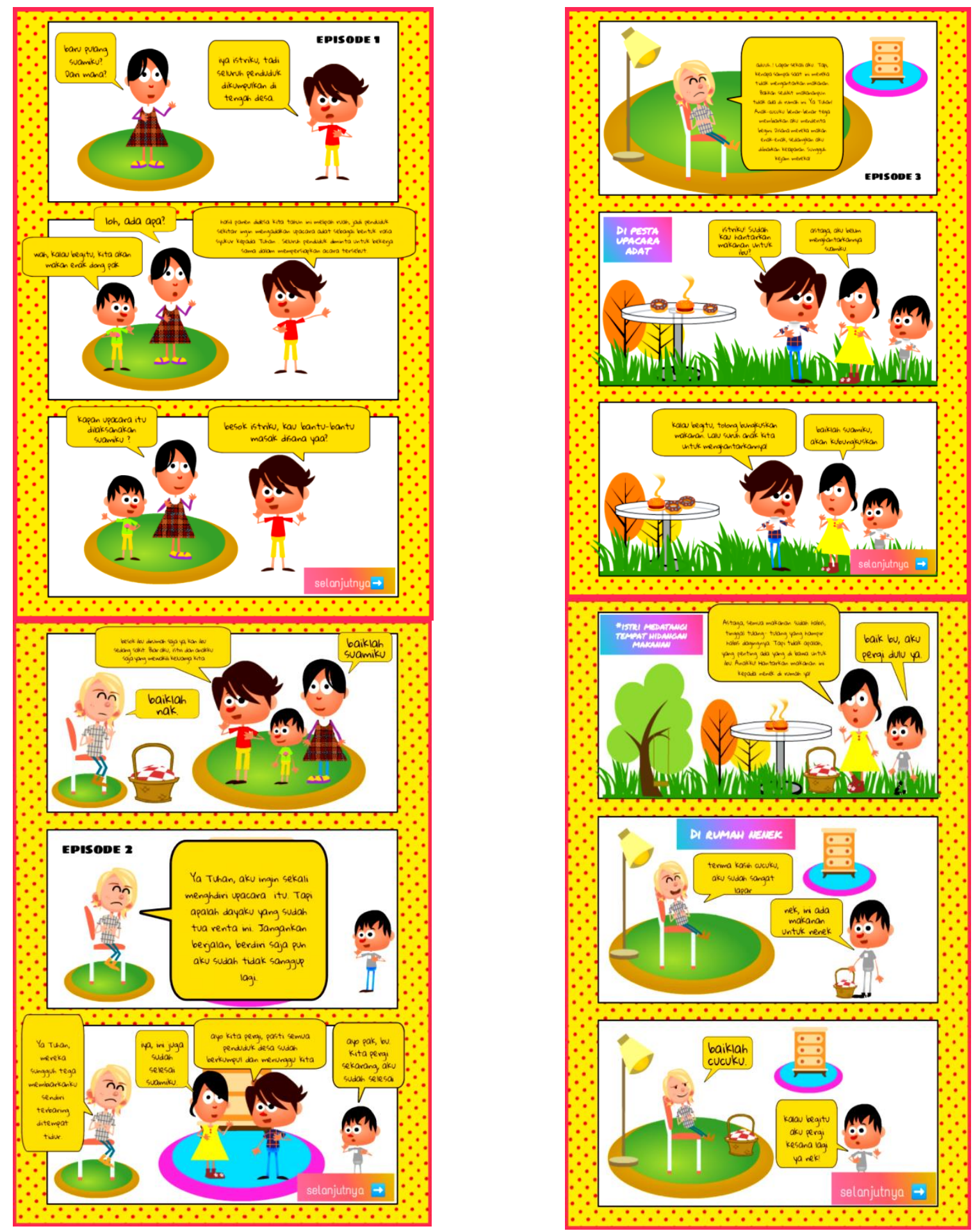


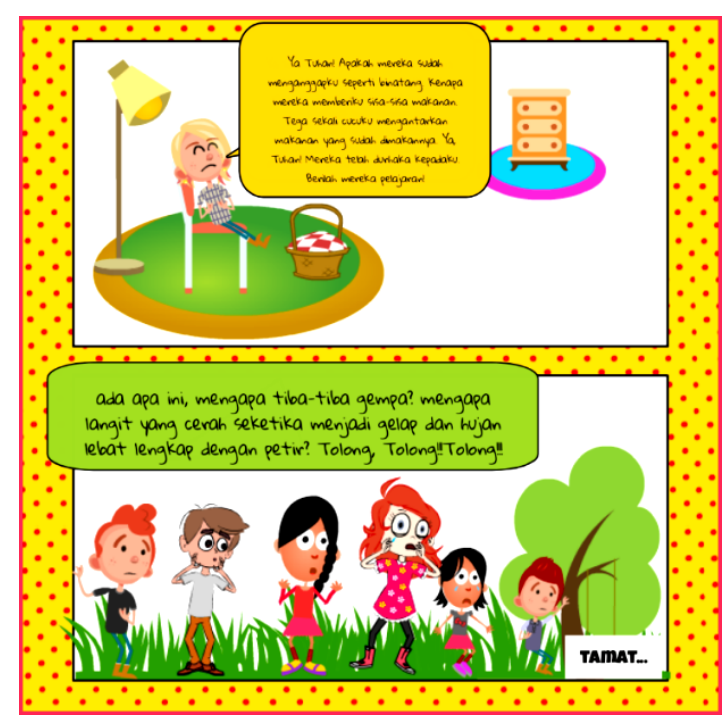

\section{Pembahasan \\ Relevansi Cerita Legenda Danau Lau Kawar}

Berikut beberapa jurnal untuk relevansi data pada judul penelitian Legenda Danau Lau Kawar Melalui Komik :

1. Perencangan Komik Digital Legenda Singo Ulung Sebagai Media Pelestarian Rakyat Kabupaten Bondowoso, yang ditulis oleh Samuel Putra Anugrah Dan Baroto Tavip Indrojarwo Departemen Desain Produk Industri, Fakultas Arsitektur Desain Dan Perencanaan Institut Teknologi Sepuluh Nopember (ITS). Dengan latar masalah semakin menurunnya budaya pendidikan lisan dengan cara mendongeng dikalangan masyarakat indonesia berdamapak pada keberadaan dan peran cerita rakyat sebagai salah satu media pengajaran nilai moral dan budi pekerti yang seharusnya akrab pada jati diri masyarakat indonesia yang bertujuan untuk meningkatkan budaya pendidikan lisan dengan cara mendongeng dikalangan masyarakat indonesia berdamapak pada keberadaan dan peran cerita rakyat sebagai salah satu media pengajaran nilai moral dan budi pekerti yang seharusnya akrab pada jati diri masyarakat indonesia dengan menghadirkan komik digital untuk memudahkan akses pengguna internet untuk mengakses komik-komik. Metode penelitian yang digunakan peneliti adalah metode kualitatif dengan wawancara dan riset eksperimental.produk yang dihasilkan adalah komik digital Legenda Singo Ulung.

2. Legenda anak durhaka: analsis Struktural tiga cerita lisan masyarakat banjar, kalimantan barat, yang ditulis oleh Rissari Yayuk Balai Bahasa Provinsi Kalimantan Selatan, Jalan A. Yani, Km 32,2, Loktabat, Banjarbaru, Kalimantan Selatan. Dengan latar masalah cerita rakyat yang disebarkan melalui lisan dan cerita tidak lagi mementingkan kebenaran dari cerita rakyat yang ada disekitar masyarakat. Dengan tujuan untuk diharapkan hasil penelitian ini akan memberi gambaran bahwa pengejawantahan pengarang terhadap alam lingkungannya ternyata mampu menghadirkan karya lisan yang bernilai sastra sekaligus mengandung pesanmoral yang dapat kita jadikan bahan instrospeksi bersama. Metode yang digunakan dalam penelitian ini adalah metode kualitatif dengan wawancara dan riset eksperimental. Produknya adalah sebagai bahan ajar terutama pada tiga cerita rakyat yang berbeda yaitu legenda yang bertemakan kedurhakaan seorang anak. Penelitian ini menelaah tiga buah sastra lisan Banjar dengan tema 
yang sama, tetapi memiliki versi dan asal yang berbeda. Sastra lisan ini berjudul "Asal Mula Batu Hapu" dari Kabupaten Tapin, "Asal Mula Sungai Pagat" dari Kabupaten Hulu Sungai Tengah, dan "Gunung Batu Bangkai" dari Kabupaten Hulu Sungai Selatan.

3. Revitalisasi Mitos Gunung Siklop (Cycloop): Sebuah Alternatif Konservasi Danau Sentani Melalui Sastra Lisan, yang ditulis oleh Sri Yono, Balai Bahasa Provinsi Papua dan Papua Barat, Jalan Yoka, Waena, Distrik Heram,Jayapura. Dengan latar masalah gunung siklop yang selalu dijadikan untuk penetian yang dapat merusak alam sekitar tanpa tahu bagaimana makna dari cerita mitos gunung siklop yang bertujuan untuk mengrevitalisasikan cerita rakyat gunung siklop untuk memuat nilai-nilai yang terkandung pada mitos gunung siklop tersebut yaitu terdapat sastra lisan sebagai pengemban amanat sosial diharapkan dapat berfungsi untuk memberi pengaruh positif terhadap orang untuk berpikir mengenai baik-buruk, benarsalah, dan cara hidupnya sendiri dan masyarakatnya. Kumpulan individu pemilik dan pendengar sastra lisan tersebut tentunya akan membentuk kelompok sosial dan akhirnya akan menghasilkan tata nilai kehidupan yang dipengaruhi oleh sastra lisan yang diharapkan. Diharapkan suatu saat nanti, sastra lisan akan menjadi salah satu sarana yang sangat ampuh untuk mengemban tata nilai kehidupan yang sesuai dengan tuntunan nilai-nilai yang dianut masyarakat. Aspek-aspek yang dimaksud adalah norma, adat istiadat,sosial budaya, didaktis, religius, dan historis. Metode yang digunakan pada penelitian ini adalah metode kualitatif melalui studi pustaka dan wawancara. Produk yang dihasilkan adalah pementasan drama mitos gunung siklop.

4. Perancangan Buku Cerita Bergambar Legenda Asal-Usul Danau Toba Untuk Anak-Anak Usia 6-10 Tahun yang ditulis oleh Jesselyn Maya, Lasiman, Maria Nala Damayanti, Program Studi Desain Komunikasi Visual, Fakultas Seni dan Desain Universitas Kristen Petra, Surabaya, Program Studi Desain Komunikasi Visual, Fakultas Seni dan Desain Institut Seni Indonesia, Yogyakarta. Dengan latar masalah legenda diapandang sebagai irrasional dan abstrak tidak dapat dipungkiri bahwa cerita Legenda Asal-Usul Danau Toba tersebut mulai ditinggalkan oleh masyarakat. Dengan menggunakan ilustrasi yang kurang menarik mengakibatkan anak tidak tertarik untuk membaca. Untuk mengatasi permasalahan tersebut, harus dirancang buku cerita yang lebih menarik dan interaktif dan yang bertujuan untuk membuat rancangan cerita bergambar sehingga mereka dapat belajar berinteraksi dengan lingkungan sekitarnya. Anak-anak usia 6-10 tahun juga mengalami perkembangan kemampuan berbahasa, oleh karena itu untuk memupuk minat baca mereka maka harus diperkenalkan dengan bacaan sejak dini walaupun dalam membaca bacaan tersebut masih memerlukan dampingan dari orang tua. Metode penelitiannya 
adalah kualitatif dengan cara wawancara, eksperimen dan analisis. Produk yang didapat adalah buku cerita bergambar asal usul danau toba.

Berikut Karakter Pada Cerita Legenda Danau Lau Kawar:

(1) Nenek, Sosok nenek pada cerita legenda danau lau kawar ini adalah seorang nenek yang sudah tua yang tidak dapat berjalan lagi yang mempunyai seorang anak perempuan dan menantu serta seorang cucu perempuan. (2) Anak Lelaki

Seorang anak yang tidak mengingat orangtuanya yang telah untuk mengahadiri pesta tahunan yang selalu dirayakan oleh masyarakat kawar namun masih mengingat ibunya untuk diberi makanan pesta adat tersebut. (3) Menantu, Seorang menantu yang melupakan ibu mertuanya yang sedang sakit dirumah . (4) Cucu, Seorang cucu yang melupakan neneknya dan seorang cucu yang serakah karena dengan rela memakan makanan yang telah dibungkus ibunya yang seharusnya untuk sang nenek dirumah.

\section{SIMPULAN}

Berdasarkan hasil penelitian yang dipaparkan pada bab sebelumnya dapat disimpulkan bahwa legengda dapat direvitalisasikan menjadi komik.

Legenda "Danau Lau Kawar" ini terbentuk karena pada zaman dahulu di sebuah Desa yang subur akan bahan pangan mengadakan upacara adat yang di rayakan oleh seluruh penduduk. Tetapi ada seorang nenek dari salah satu keluarga yang tidak dapat mengikuti acara upacara adat tersebut. Sehingga yang mewkili hanya anak, menantu dan cucu. Namun mereka melupakan nenek dan membiarkan kelaparan seorang diri. Setelah acara adat selesai anak mengingat ibunya yang kelaparan di rumah, kemudian anak memerintahkan istrinya untuk menghantarkan makanan namun, makanan yang tesisa hanya tulang-tulang yang masih ada sedikit dagingnya. Namun istri tetap membungkuskan sisa makanan itu dan menyuruh anak untuk menghantarkan makanan itu ke rumah. Sesampainya di rumah nenek membuka bungkusan dan melihat di dalamnya hanya sisa makanan. Nenek merasa terhina dan akhirnya nenek mengutuk desa tersebut.

Legenda "Danau Lau Kawar" yang telah disusun peneliti berdasarkan akurasi dari para informan dan penduduk sekitar Desa Kawar, selanjutnya direvitalisasikan menjadi komik

\section{DAFTAR PUSTAKA}

Danandjaja, James. (2002). Folklor Indonesia: Ilmu gosip, dongeng, dan lain-lain. Jakarta: Grafiti.

Sugiyono, 2009, Metode Penelitian Kuantitatif, Kualitatif dan $R \& D$, Bandung: Alfabeta

Miles, M.B. and Humbermen, M.A. 1984. Qualitative Data Analysis, London: Sage Publication.

Samuel Putra Anugrah Dan Baroto Tavip Indrojarwo, "Perencangan Komik Digital Legenda Singo Ulung Sebagai Media Pelestarian Rakyat Kabupaten Bondowoso". Skripsi program study Departemen Desain Produk Industri, Fakultas Arsitektur Desain Dan Perencanaan Institut Teknologi Sepuluh Nopember (ITS).

Rissari Yayuk, "Legenda anak durhaka: analsis Struktural tiga cerita lisan masyarakat banjar, kalimantan barat”. Balai Bahasa Provinsi Kalimantan Selatan.

Sri Yono, "Revitalisasi Mitos Gunung Siklop (Cycloop): Sebuah Alternatif Konservasi Danau Sentani Melalui Sastra Lisan". Balai Bahasa Provinsi Papua dan 
Papua Barat, Jalan Yoka, Waena, Distrik Heram, Jayapura.

Jesselyn Maya, Lasiman, Maria Nala Damayanti, "Perancangan Buku Cerita Bergambar Legenda AsalUsul Danau Toba Untuk AnakAnak Usia 6-10 Tahun". Program Studi Desain Komunikasi Visual, Fakultas Seni dan Desain Universitas Kristen Petra, Surabaya, Program Studi Desain Komunikasi Visual, Fakultas Seni dan Desain Institut Seni Indonesia, Yogyakarta. 